\title{
Do partial AZFc deletions affect the sperm retrieval rate in non-mosaic Klinefelter patients undergoing microdissection testicular sperm extraction?
}

\author{
I-Shen Huang 1,2,3,4, Richard J. Fantus ${ }^{5}$, Wei-Jen Chen 2,3,4, James Wren ${ }^{6}$, Wei-Tang Kao ${ }^{7,8}$, Eric Yi-Hsiu Huang ${ }^{2,3,4}$,
} Nelson E. Bennett ${ }^{6}$, Robert E. Brannigan ${ }^{6}$ and William J. Huang ${ }^{1,2,3,4^{*}}$

\begin{abstract}
Background: The purpose of this study is to evaluate the prognostic factors for sperm retrieval and determine if $Y$ chromosome deletion is associated with deleterious effects on spermatogenesis in non-mosaic Klinefelter patients. Whether $Y$ chromosome deletion determines the sperm retrieval rate in non-mosaic Klinefelter patients has not yet been addressed.

Methods: We retrospectively collected medical records of azoospermic patients from Sep 2009 to Dec 2018, and enrolled 66 non-mosaic 47, XXY patients who were receiving mTESE. The predictive values of patients age, serum follicle-stimulating hormone (FSH), luteinizing hormone (LH), testosterone, prolactin, estradiol and $Y$ chromosome deletion were assessed for successful sperm recovery.

Results: Testicular sperm recovery was successful in 24 (36.4\%) of 66 men. The mean age (36.0 vs. 36.6 years), and levels of FSH (30.0 vs $36.9 \mathrm{IU} / \mathrm{L})$, LH (17.7 vs $21.9 \mathrm{IU} / \mathrm{L})$, testosterone (2.4 vs. $2.1 \mathrm{ng} / \mathrm{ml})$, prolactin $(9.1 \mathrm{vs.} 8.8 \mathrm{ng} / \mathrm{ml})$, and estradiol (19.4 vs. $22.3 \mathrm{pg} / \mathrm{ml}$ ) did not show any significant difference when comparing patients with and without successful sperm retrieval. Partial deletion of azoospermic factor c (AZFc) was noted in 5 (20.8\%) of 24 patients with successful sperm retrieval, including three b2/b3 and two gr/gr deletion cases, whereas 4 (9.5\%) of 42 patients with unsuccessful sperm retrieval were noted to have AZFc partial deletion (one b2/b3, one sY1206 and two $\mathrm{gr} / \mathrm{gr}$ deletion), though the difference was not statistically significant ( $p=0.27)$.
\end{abstract}

Conclusion: According to present results, age and AZFc partial deletion status should not be a deterrent for azoospermic males with non-mosaic Klinefelter syndrome to undergo mTESE.

Keywords: Klinefelter, AZFc deletion, Age, Microdissection testicular sperm extraction

\section{Background}

According to recommendations from the American Society for Reproductive Medicine (ASRM) and European Association of Urology (EAU), cytogenetic analysis is suggested for patients with azoospermia or oligozoospermia. However, the threshold of sperm count recommended for karyotype analysis differs between the two

\footnotetext{
* Correspondence: williamjshuang@gmail.com

'Department of Physiology, School of Medicine, National Yang-Ming University, Taipei, Taiwan

2Department of Urology, School of Medicine, National Yang-Ming University, Taipei, Taiwan

Full list of author information is available at the end of the article
}

associations: spermatozoa count below 10 million/mL from the EAU and spermatozoa count below 5 million/ $\mathrm{mL}$ from the ASRM $[1,2]$. The main purpose of performing cytogenetic analysis for patients with subfertility or infertility is to provide proper counselling before assisted reproductive technology and inform couples of possible inheritances of paternal genetic disorders in their offspring.

Genetic mutation or chromosome abnormality is more common in infertile males than in the general population, and investigations have shown that the percentage of chromosome abnormalities and Y chromosome

(C) The Author(s). 2020 Open Access This article is distributed under the terms of the Creative Commons Attribution 4.0 International License (http://creativecommons.org/licenses/by/4.0/), which permits unrestricted use, distribution, and 
microdeletions is about $2-6 \%$ and $3-5 \%$ [3, 4] for oligospermic patients, $13-15 \%$ and $6-16 \%$ for non-obstructive azoospermia (NOA) patients [5, 6]. Among all chromosome abnormalities, Klinefelter syndrome (KS) is the most common numerical chromosome abnormality found in infertile men with an incidence rate of about 1in-500 to 1-in-1000 male birth [7]. The majority of cases with 47, XXY non-mosaic Klinefelter karyotype will present as hypergonadotropic hypogonadism and azoospermia, regardless of age, as a sign of primary testicular failure [8]. However, aside from the non-mosaic form, there is a strong probability of finding sperm in semen with mosaic form (46, XY/47, XXY) of KS, depending on the level of XXY cell line mosaicism in the gonads [9]. In general, about $90 \%$ of patients have uniform 47 , XXY karyotype (pure KS) in which an extra X chromosome is present in somatic and germ cells, while $10 \%$ of KS can present with higher-grade of $\mathrm{X}$ chromosome aneuploidies (48 or more chromosomes) as well as mosaicism (47, XXY/46, XY) [7]. Mosaic KS men tend to be more androgenized than their non-mosaic KS counterparts in terms of hormone profile and sperm count in ejaculate, representing better fertility potential, especially in lowgrade mosaicism form [9].

The azoospermia factor (AZF) region on the $\mathrm{Y}$ chromosome long arm is crucial for spermatogenesis and is known for its unique nearly identical direct and indirect repeated palindromic sequences. In addition to $\mathrm{KS}$, the deletion of AZF is another cause for male infertility [10]. Removal of the spermatogenesis candidate gene located in the AZFa or AZFb, which is responsible for production of male gametes, namely the USP9Y, DDX3Y, RBMY and PRY genes, will inevitably lead to spermatogenic failure and therefore is not recommended for microdissection testicular sperm extraction (mTESE) due to the lack of identifiable regions of spermatogenesis in the testes [11]. The result of semen analysis of men with AZFc deletion varies in comparison with azoospermia found in AZFa and AZFb men, ranging from azoospermia to moderate oligozoospermia. Despite causing detrimental effects in sperm production, AZFc deletion is still regarded as a good prognostic factor for azoospermic men; the sperm retrieval rate (SRR) is up to $70 \%$ in this population [12].

The incidence of AZFc deletion is higher than incidence of AZFa or AZFb deletion in men, because the $\mathrm{Y}$ chromosome AZFc region is predisposed to intrachromosomal non-allelic homologous recombination owing to its composition of large repeat units called "amplicons" [13].

Rearrangement of the AZFc region, including partial deletions, duplications and deletions followed by duplication(s) has been reported [13]. Deletion of the entire AZFc locus on the $\mathrm{Y}$ chromosome by means of removing $3.5 \mathrm{Mb}$ segment, including eight multi-copy gene families, is consensually considered a cause for infertility $[10,14]$. As for AZFc partial deletion, $\mathrm{Gr} / \mathrm{gr}$ deletion is the most common type, followed by b2/b3 and b1/b3 deletions. In particular, whether gr/gr deletion causes deleterious effects on spermatogenesis is still an ongoing debate. According to previous literature, the frequency of gr/gr deletion is only higher in certain azoospermia or oligozoospermia populations in Italy and China when compared to the control $[15,16]$.

Researchers have attempted to find predictors for successful sperm retrieval in KS men; some have demonstrated that testosterone levels after medical treatment, including aromatase inhibitors, clomiphene or human chorionic gonadotropin [17] and age at time of mTESE are reliable prognostic factors [18]. Therefore, they have recommended that patients receive mTESE for sperm retrieval under the age of 35 [18]. To date, due to the limited number of KS men, there are a paucity of articles discussing sperm retrieval rate by mTESE. Moreover, previous study populations did not include Han-Chinese or whether Y chromosome microdeletion may serve as a prognostic factor for possible sperm retrieval. Some clinicians may infer the outcome of sperm retrieval is affected by $\mathrm{Y}$ chromosome microdeletion in Klinefelter patients. Our study aimed to analyze predictive factors for sperm retrieval in Han-Chinese KS men and discuss the association for $\mathrm{Y}$ chromosome microdeletion with successful sperm retrieval.

\section{Methods}

\section{Studied populations}

We retrospectively reviewed the period between September 2009 to Dec 2018. A total of 66 non-mosaic Klinefelter patients who were receiving microdissection testicular sperm extraction were enrolled in our study. All subjects were genetically ethnic Han-Chinese from Taiwan. Each patient underwent a detailed examination to identify the etiology of azoospermia, including a detailed history, physical examination, two consecutive semen analyses, hormone profile (follicle stimulating hormone (FSH), leutinizing hormone (LH), testosterone and prolactin), chromosome karyotyping, and Y chromosome microdeletion. DNA samples of 107 fertile controls who had fathered at least one child were obtained from 2 medical centers in Taiwan as described by Lin et al. in 2007 [14]. This study was performed according to the Taipei Veterans General Hospital approved Institutional Review Board protocol (IRB number: 2018-03-002CCF).

\section{DNA extraction}

Genomic DNA was extracted from peripheral blood using the QIAamp DNA minikit (Qiagen, Hilden, Germany) according to the manufacturer recommendations. In brief, 
$20 \mu \mathrm{l}$ Qiagen protease was pipetted into the bottom of a $1.5 \mathrm{ml}$ microcentrifuge tube, then up to $200 \mu \mathrm{l}$ whole blood or buffy coat was added to the microcentrifuge tube. After the addition of $200 \mu \mathrm{l}$ buffer AL to the sample, the sample was thoroughly mixed by vortex mixing and was incubated at $56^{\circ} \mathrm{C}$ for $10 \mathrm{~min}$ until cell lysis was complete. Two hundred microliters of ethanol (100\%) were added to precipitate the DNA. The mixture was carefully applied to the QIAamp spin column, placed inside a $2 \mathrm{ml}$ collection tube, and centrifuged at $8000 \mathrm{rpm}, 6000 \times \mathrm{g}$ for $1 \mathrm{~min}$. The QIAamp Spin column was then placed in a new collection tube, and $500 \mu \mathrm{l}$ of buffer, AW1 was added and centrifuged. This step was repeated with the buffer AW2 and a high spin was given for $3 \mathrm{~min}$ to dry the column membrane. The spin column was subsequently placed in a clean $1.5 \mathrm{ml}$ microcentrifuge tube, and the DNA filtrate was recovered with $200 \mu \mathrm{l}$ of buffer AE. Following centrifugation, DNA was eluted and stored at $-20^{\circ} \mathrm{C}$ until used.

\section{Cytogenetic analysis}

Chromosome analysis was performed using conventional trypsin-Giemsa banding technique. Twenty metaphases were analyzed for each patient, and in cases of suspected mosaicism, the number of metaphases was increased to a total of 50 for analysis. To achieve a more detailed analysis, a 500-550 band level was used for evaluation.

\section{Yq classical deletions and AZFc subdeletions}

$Y$ microdeletion screening in Klinefelter patients was performed by multiplex polymerase chain reaction (PCR) that detects markers in the AZF regions, the sex determining region $Y$ (SRY) gene, and the $Y$ homologous gene pair zinc-finger Y (ZFY) [19]. The sequence-tagged sites (STS) selected are listed in Fig. 1 and Table 1. Six AZFc deletions (sY254, sY1161, sY1191, sY1201, sY1206, and sY1291) were used to identify the type of partial AZFc deletions in all subjects. In addition, DNA from fertile males and female served as positive and negative controls, respectively. Ambiguities in the multiplex PCR assays were resolved by following up with single PCR assays.

\section{Microdissection testicular sperm extraction}

A small incision $(3 \mathrm{~cm})$ was made longitudinally on the median raphe, and carried down to the fascia. The testis were mobilized after opening the tunica vaginalis as described in 1999 [20]. We performed a longitudinal incision on the testis instead of open it widely in an equatorial plane along the mid portion of the testis. An operating microscope with $20 \mathrm{x} \sim 24 \mathrm{x}$ magnification allow the surgeon to identify larger and opaquer seminiferous tubules, which are most likely to contain sperm. Tissue with possibility of spermatogenesis was removed and sent for real time analysis by experienced embryologists in our reproductive lab for further intracytoplasmic sperm injection (ICSI).

\section{Statistical analysis}

Outcome variables (age, serum FSH, LH, testosterone, prolactin and estradiol) of azoospermic non-mosaic KS men with successful surgical sperm retrieval were compared to those with unsuccessful sperm retrieval using the Student's t test. The distributions of AZFc partial deletion of Klinefelter patient with or without sperm retrieval and the frequency of AZFc partial deletion comparing azoospermic non-mosaic Klinefelter men with controls were analyzed by the Fisher's exact test. In these tests, values of $p<0.05$ were regarded as statistically significant.

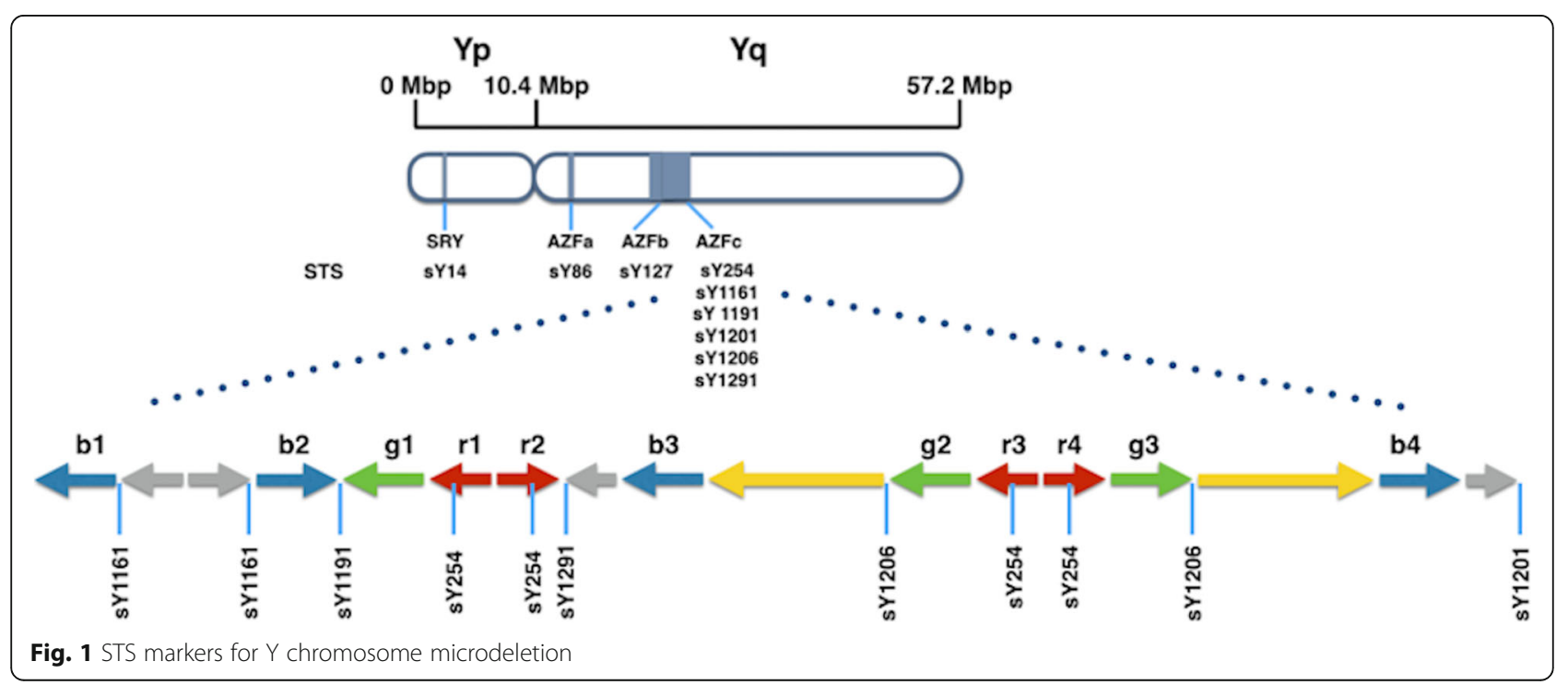


Table 1 Sequence of 10 sets of primer employed to identify Y-chromosome microdeletions

\begin{tabular}{|c|c|c|c|}
\hline STS/gene & Primer sequence & Product size (bp) & Region \\
\hline SRY-F & 5' - GAA TAT TCC CGC TCT CCG GA - 3' & 495 & NRY \\
\hline SRY-R & 5' - GCT GGT GCT CCA TTC TTG AG - 3' & & \\
\hline ZFY-F & $5^{\prime}$ - ACC RCT GTA CTG ACT GTG ATT ACA C - 3' & 472 & NRY \\
\hline ZFY-R & 5' - GCA CYT CTT TGG TAT CYG AGA AAG T - 3' & & \\
\hline sY86-F & $5^{\prime}$ - GTG ACA CAC AGA CTA TGC TTC - 3' & 320 & AZFa \\
\hline sY86-R & $5^{\prime}$ - ACA CAC AGA GGG ACA ACC CT - 3' & & \\
\hline sY127-F & $5^{\prime}$ - GGC TCA CAA ACG AAA AGA AA - 3' & 274 & $\mathrm{AZFb}$ \\
\hline sY127-R & $5^{\prime}$ - CTG CAG GCA GTA ATA AGG GA - 3' & & \\
\hline sY254-F & $5^{\prime}$ - GGG TGT TAC CAG AAG GCA AA - 3' & 400 & AZFC \\
\hline sY254-R & $5^{\prime}$ - GAA CCG TAT CTA CCA AAG CAG C - 3' & & \\
\hline sY1161-F & $5^{\prime}$ - CGA CAC TाT TGG GAA GTT TCA - 3' & 377 & AZFC \\
\hline sY1161-R & $5^{\prime}$ - TTG TGT CCA GTG GTG GCT TA- 3' & & \\
\hline sY1191-F & $5^{\prime}-$ CCA GAC GTT CTA CCC TाT CG - 3' & 385 & AZFC \\
\hline sY1191-R & $5^{\prime}$ - GAG CCG AGA TCC AGT TAC CA - 3' & & \\
\hline sY1201-F & $5^{\prime}$ - CCG ACT TCC ACA ATG GCT - 3' & 677 & AZFC \\
\hline sY1201-R & $5^{\prime}$ - GGG AGA AAA GTT CTG CAA CG - 3' & & \\
\hline sY1206-F & 5' - ATT GAT CTC CTT GGT TCC CC - 3' & 394 & AZFC \\
\hline sY1206-R & $5^{\prime}$ - GAC ATG TGT GGC CAA TTT GA - 3 & & \\
\hline sY1291-F & $5^{\prime}$ - TAA AAG GCA GAA CTG CCA GG - 3' & 527 & AZFC \\
\hline sY1291-R & $5^{\prime}$ - GGG AGA AAA GTT CTG CAA CG - 3' & & \\
\hline
\end{tabular}

\section{Results}

\section{Azoopsermic non-mosaic Klinefelter men and $Y$ chromosome deletion}

The cohort of 66 azoospermic non-mosaic Klinefelter men with chromosome 47, XXY had a mean age of $36.4 \pm 5.2$ years (mean $\pm \mathrm{SD}$ ). Of these 66 men, 9 men (13.6\%) had a deletion of one STS marker. More precisely, we identified 5 men with an absence of sY1291 (possible $g r / g r$ deletion), 3 men with an absence of sY1191 (possible $b 2 / b 3$ deletion) and 1 with an absence of sY1206 only. Of the 24 patients with successful sperm retrieval, 5 (20.8\%) had partial AZFc deletion, including 2 possible $g r / g r$ deletion and 3 possible $b 2 / b 3$ deletion cases (Table 2). Partial AZFc deletion is identified in 4 (9.5\%) of 42 patients without sperm retrieval by mTESE, (one possible $b 2 / b 3$, one sY1206, and two possible $g r / g r$ deletion), though the difference of $\mathrm{Y}$ chromosome deletion was not statistically significant between the successful and non-successful sperm retrieval groups $(p=0.27)$.

\section{Impact of various parameters on mTESE success}

Of the non-mosaic KS patients, mTESE was successful in 24 out of 66 patients, representing 36.4\% of cases. Table 2 lists the clinical factors analyzed to predict sperm retrieval, stratified by outcome. Age, partial AZFc deletions, and hormone parameter $(\mathrm{LH}, \mathrm{FSH}$, testosterone, prolactin, estradiol) were not predictive factors for successful sperm retrieval.

\section{Effect of age on sperm retrieval}

SRR for mTESE was 34.6\% (9/26) at ages below 35 years and $37.5 \%(15 / 40)$ at 35 years and older. Four of $13 \mathrm{KS}$ men older than 40 years of age had successful sperm retrieval; the oldest patient with successful mTESE was 47 years-old (Fig. 2).

Table 2 Demographic profile of nonmosaic Klinefelter men with positive and negative MTESE outcome

\begin{tabular}{lllll}
\hline & $\begin{array}{l}\text { Overall } \\
\text { Mean } \pm \text { SD }\end{array}$ & $\begin{array}{l}\text { mTESE (+) } \\
\text { Mean } \pm \text { SD }\end{array}$ & $\begin{array}{l}\text { mTESE }(-) \\
\text { Mean } \pm \text { SD }\end{array}$ & p value \\
\hline Number & $n=66$ & $n=24$ & $n=42$ & \\
Age (yr) & $36.4 \pm 5.2$ & $36.0 \pm 4.9$ & $36.6 \pm 5.4$ & 0.67 \\
FSH (IU/L) & $34.3 \pm 17.0$ & $30.0 \pm 13.1$ & $36.9 \pm 18.6$ & 0.12 \\
LH (IU/L) & $20.4 \pm 11.7$ & $17.7 \pm 9.7$ & $21.9 \pm 12.6$ & 0.16 \\
Testosterone (ng/nl) & $2.2 \pm 1.8$ & $2.4 \pm 2.0$ & $2.1 \pm 1.6$ & 0.47 \\
Prolactin & $9.2 \pm 3.7$ & $8.7 \pm 3.5$ & $9.5 \pm 3.8$ & 0.39 \\
Estradiol (pg/ml) & $21.0 \pm 9.9$ & $19.5 \pm 7.4$ & $21.8 \pm 11.0$ & 0.41 \\
Y partial deletion & $9(13.6 \%)$ & $5(20.8 \%)$ & $4(9.5 \%)$ & 0.27 \\
\multicolumn{1}{c}{ gr/gr deletion } & $4(6.1 \%)$ & $2(8.3 \%)$ & $2(4.8 \%)$ & 0.62 \\
b2/b3 deletion & $4(6.1 \%)$ & $3(12.5 \%)$ & $1(2.4 \%)$ & 0.13 \\
sY1206 deletion & $1(1.5 \%)$ & $0(0 \%)$ & $1(2.4 \%)$ & 1.00 \\
\hline
\end{tabular}




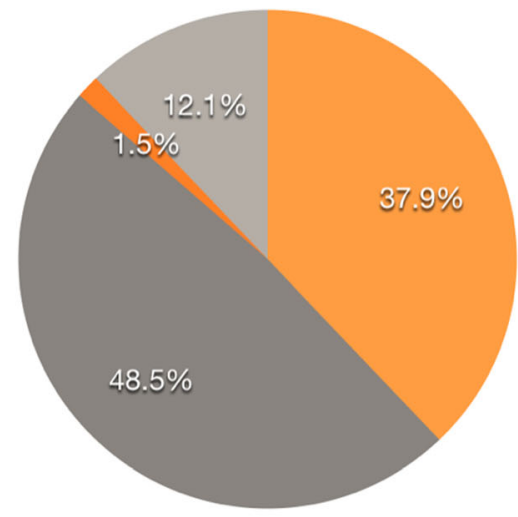

age $<35$ years without partial $Y$ chromosome deletion $(n=25)$

age $\geq 35$ years without partial $Y$ chromosome deletion $(n=32)$

age $<35$ years with partial $Y$ chromosome deletion $(n=1)$

age $\geq 35$ years with partial $Y$ chromosome deletion $(n=8)$

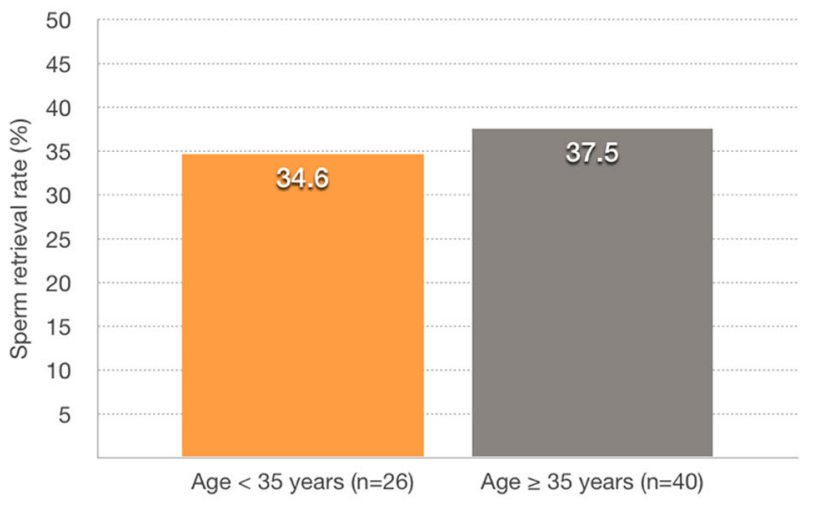

Age $<35$ years $(n=26)$

Age $\geq 35$ years $(n=40)$

Fig. 2 Percentage of KS men below and above 35 with $Y$ chromosome deletion and sperm retrieval rate by mTESE

\section{Partial AZFc deletions distribution between the experimental and control groups}

The frequency of AZFc partial detection was 13.6\% (9/ $66)$ in $\mathrm{KS}$ men and 6.5\% (7/107) in the control, although a higher percentage was seen in $\mathrm{KS}$ men, however the difference was not statistically significant $(p>0.05)$. The deletion pattern in $9 \mathrm{KS}$ men with AZFc partial deletion included 4 men with possible $g r / g r$ deletion, 4 with possible $b 2 / b 3$ deletion, and one with sY1206 deletion. Seven men in the control group with AZFc partial deletion included 3 men with possible $g r / g r$ deletion and 4 men with possible $b 2 / b 3$ deletion. There was no significant difference between the frequencies of specific AZFc partial deletion pattern by means of possible $g r / g r$, possible $b 2 / b 3$, and sY1206 deletion, respectively (Table 3). $\mathrm{Y}$ chromosome partial deletion was detected in $5 \mathrm{KS}$ men with successful sperm retrieval.

\section{Discussion}

The extra $\mathrm{X}$ chromosome in $\mathrm{KS}$ men causes germ cell degeneration and adverse effects to somatic cells, including Leydig and Sertoli cells, resulting in infertility. As a matter of fact, germ cell degeneration take place early in the fetal period, whereas the density and number of seminiferous tubules and mesenchymal tissues remain normal, without obvious pattern change [21]. The hormone levels are unaffected until the onset of puberty, which is when the germ cell depletion, Sertoli cell degeneration, Leydig cell hyperplasia and seminiferous tubule hyalinization initiate and accelerate [22]. Accelerated degeneration of the Sertoli cell is also evidenced by the sign of aberrant nuclear expression of the $\alpha$-subunit in the Sertoli cells in older teenage KS boys
[23]. Based on the concept of early fertility deterioration, sperm banking at a younger age is recommended at puberty, according to their Tanner stage. The results, however, were not promising with regards to $\mathrm{KS}$ adolescent semen quality. Sperm in the ejaculate can only be detected in limited cases [8].

If sperm cannot be traced in the semen, using mTESE for testicular sperm retrieval associated with assisted reproductive technology such as ICSI is a recommended option with a satisfactory outcome, and offers these patients the opportunity to father biological children. As shown in several studies, age is a predictive factor for successful sperm retrieval in KS men receiving mTESE; In adult men younger than 35 years old, sperm retrieval rate (SRR) is reported to range from 30 to $77 \%$, with a higher SRR than subjects $>35$ years. Consequently, experts recommend performing mTESE under the critical age of 35 or even 30 years to yield a better outcome [18, 24]. However, age as a predictive factor for sperm retrieval was not unanimously proved in other literatures $[25,26]$. In our study, age was not a predictive factor for sperm retrieval, and SRR was comparable for KS men under or above the age of $35(33.3 \%$ vs $37.5 \%$, respectively). The mean age of our study population is 36.4

Table 3 AZFc partial deletion in KS men and controls

\begin{tabular}{llll}
\hline & Fertile control & Klinefelter men & $p$ value \\
\hline Total subjects & 107 & 66 & \\
AZFc partial deletion & 7 & 9 & 0.18 \\
gr/gr deletion & 3 & 4 & 0.43 \\
b2/b3 deletion & 4 & 4 & 0.48 \\
sY1206 deletion & 0 & 1 & 0.38 \\
\hline
\end{tabular}


years; only two KS men (age 25 and 27 years) under the age of 30 was evaluated, which will limit the ability to evaluate the influence of age on successful sperm retrieval.

Our Klinefelter cases with older age may be explained by the fact that a majority of cases coming to our center are either referral or consultation for infertility other than delayed puberty, which also implies that most of the Taiwanese KS men remained undiagnosed before marriage. According to Taiwanese government statistics, the average age of marriage for men has increased in the last decade and was 34.2 years in 2015 .

$g r / g r$ deletion, the most common form of partial AZFc deletion, has been demonstrated a correlation with male infertility in many meta-analysis studies $[27,28]$. However, debates rage over whether $g r / g r$ deletion and copy number reduction of AZFc genes influence spermatogenesis. The diverse phenotypes in $g r / g r$ deletion prevent researchers from drawing definite conclusions on this topic, which is best shown in the Japanese population with $33.9 \% \mathrm{gr} / \mathrm{gr}$ deletion men in the control group, and $23.9 \%$ in the infertility group, although the controls have unknown fertility status [29]. Based on ethnicity and region, Caucasians $(\mathrm{OR}=3.721)$, people from Europe $(\mathrm{OR}=2.465)$, and people from South Asia $(\mathrm{OR}=2.523)$ with $g r / g r$ deletion had a higher risk of male infertility in comparison to those without deletions [28]. But published literatures within the same ethnicity have drawn opposite conclusions. In China, $\mathrm{Wu}$ et al. pointed out that $b 2 / b 3$ deletion was significantly associated with idiopathic male infertility [30], while in contrast, Yang et al. recorded $g r / g r$ deletion, instead of $b 2 / b 3$ deletion, serve as a more important anomaly in determining the susceptibility to spermatogenic failure [31].

As a matter of fact, the results may vary without contradiction. Two study populations that were $1500 \mathrm{~km}$ apart belonged to different $\mathrm{Y}$ chromosome haplogroup, representing distinct paternal lineage. As demonstrated previously, Y lineages as defined by different haplotypes could influence the phenotypical expression of identical $g r / g r$ deletion genotype [32]. $G r / g r$ deletions and $b 2 / b 3$ have been demonstrated fixed in haplogroup Q1 and haplogroup N; the prevalence of partial deletion will likely mask actual influence from other haplogroups [14, 27, 33, 34]. In the Taiwanese population, Lin et al. found that $14 \%$ of men have deletions and duplications of AZFc and that the frequency of deletion vary between different $Y$ haplogroups, ranging from $2.9 \%$ in O3e to $100 \%$ in N and Q [14]. AZFc partial duplication other than partial deletion increases the risk of spermatogenic failure. Although, in our study, we did not perform quantitative PCR analysis to evaluate DAZ (Deleted in AZoospermia) dosage and duplication in our patients, with regard of the presence of AZFc, partial deletion did not seem to affect SRR.
In Danish and Chinese populations, specific Y haplogroup has been suggested to be an "at risk $\mathrm{Y}$ haplogroup" by their over-presentation in the spermatogenic impairment population [31, 35]. Until now, no study has looked into the relationship between different $\mathrm{Y}$ haplogroup and SRR in azoospermic cases. Hence, it would be interesting to understand the possible influence of $Y$ haplogroup not only on semen parameters but also on spermatogenesis in the testes.

We examined Y chromosome microdeletions in KS men using 10 sets of primers and detected 9 cases with partial AZFc deletion, including 4 men with possible $g r / g r$ deletion, 4 with possible $b 2 / b 3$ deletion, and one with sY1206 deletion KS. Our study did not detect complete AZFa, AZFb or AZFc deletion in KS men, which is compatible with the Lin et al. study, suggesting a low percentage of complete deletion pattern in Han Chinese in Taiwan [14]. The incidence of AZFc partial deletion did not differ between the KS men and the fertility control men; the result is consistent with a recent study investigating AZF microdeletion in KS men [36]. However, in a study of Han Chinese KS men in China, the proportion of partial AZFc deletion is higher than our population - $27(24.3 \%)$ of $111 \mathrm{KS}$ men and 11 (11.7\%) of the 94 controls compared to our population of $13.6 \%$ in KS men and $6.5 \%$ in the control [36]. The outcome of our study indicates that the possible $g r / g r$ and $b 2 / b 3$ deletions are not correlated with KS men in the Taiwan HanChinese population, suggesting that although formation of sperm with an extra copy of $\mathrm{X}$ chromosome by nondisjunction during meiosis I contributed to paternal error, it did not increase the chance of de novo $\mathrm{Y}$ chromosome partial microdeletion.

Previous studies on the preoperative hCG or aromatase inhibitor on KS men have demonstrated varying results, therefore our KS cases were not routinely given hCG or aromatase inhibitors before mTESE $[17,24,26]$.. Prior experience with mTESE in KS men with non-obstructive azoospermia reported SRR range from 16 to $70 \%$ and cumulative SRR per TESE cycle of 44\% [37]. The SRR for KS men above 35 years of age in 3 series were 25, 30 and $50 \%$; it was $37.5 \%$ in our study $[17,18,24]$.

To our knowledge this is the first article looking into $\mathrm{Y}$ chromosome deletion in Klinefelter patients for SRR evaluation. Our results demonstrate that AZFc partial deletion, age, and endocrine variables do not predict sperm retrieval in KS men. Sperm retrieval rate is comparable for men below and above 35 years, and we should not discourage AZFc partial deletion men or men over the age of 35 from accepting mTESE for possible sperm retrieval.

\section{Conclusion}

According to present results, age and AZFc partial deletion status should not be a deterrent for azoospermic 


\section{males with non-mosaic Klinefelter syndrome to undergo} mTESE.

\section{Abbreviations}

ASRM: American Society for Reproductive Medicine; AZF: Azoospermia factor; DAZ: Deleted in AZoospermia; EAU: European Association of Urology; FSH: Follicle stimulating hormone; ICSI: Intracytoplasmic sperm injection; KS: Klinefelter syndrome; LH: Leutinizing hormone; mTESE: Microsurgical testicular sperm extraction; NAHR: Non-allelic homologous recombination; NOA: Non-obstructive azoospermia; PCR: Polymerase chain reaction; SRR: Sperm retrieval rate; SRY: Sex determining region Y; STS: Sequencetagged sites; ZFY: Zinc-finger $Y$

\section{Acknowledgements}

Not applicable.

\section{Authors' contributions}

IH contributed to study conception and design. WC, JW, WK, EH contributed to data acquisition. $\mathrm{IH}$ contributed to analysis and interpretation of data. $I \mathrm{H}$, RF contributed to drafting the manuscript. NB, RB, WH were involved in revising the manuscript. All authors have read and approved the manuscript.

\section{Funding}

Taipei Veterans General Hospital-National Yang-Ming University Excellent Physician Scientist Cultivation Program, No. 108-V-B-024.

Taipei Veterans General Hospital V108C-141.

\section{Availability of data and materials}

The data that support the findings of this study are available on request from the corresponding author W.H. The data are not publicly available due to them containing information that could compromise research participant privacy.

\section{Ethics approval and consent to participate}

All procedures performed in studies involving human participants were in accordance with the ethical standards of the institutional research committee and with the 1964 Helsinki declaration and its later amendments or comparable ethical standards. This study was approved by the local ethics committee at the "Taipei Veterans General Hospital", Taiwan, reference no. 2018-03-002-CCF. For this type of retrospective study formal consent is not required.

\section{Consent for publication}

Not applicable.

\section{Competing interests}

The authors declare that they have no competing interests.

\section{Author details}

${ }^{1}$ Department of Physiology, School of Medicine, National Yang-Ming University, Taipei, Taiwan. 'Department of Urology, School of Medicine, National Yang-Ming University, Taipei, Taiwan. ${ }^{3}$ Department of Urology, Taipei Veterans General Hospital, No 201, Section 2, Shipai Rd, Taipei 112 , Taiwan, Republic of China. ${ }^{4}$ Department of Urology, School of Medicine, Shu-Tien Urological Research Center, National Yang-Ming University, Taipei, Taiwan. ${ }^{5}$ Section of Urology, Department of Surgery, University of Chicago Medicine, 5841 S. Maryland Avenue, Chicago, IL 60637, USA. ${ }^{6}$ Division of Male Reproductive Surgery and Men's Health, Department of Urology, Northwestern University Feinberg School of Medicine, NMH/Arkes Family Pavilion Suite 2300, 676 N Saint Clair, Chicago, IL 60611, USA. ${ }^{7}$ Department of Urology, Shuang Ho Hospital, Taipei Medical University, No.291, Zhongzheng Rd., Zhonghe District, New Taipei City 23561, Taiwan. ${ }^{8}$ Graduate Institute of Clinical Medicine, Taipei Medical University, New Taipei City, Taiwan.

Received: 18 September 2019 Accepted: 17 February 2020 Published online: 27 February 2020

\section{References}

1. Medicine PCoASfR. Diagnostic evaluation of the infertile male: a committee opinion. Fertil Steril. 2012;98(2):294-301.
2. Jungwirth A, Giwercman A, Tournaye H, Diemer T, Kopa Z, Dohle G, et al. European Association of Urology guidelines on male infertility: the 2012 update. Eur Urol. 2012;62(2):324-32.

3. Van Assche $E$, Bonduelle $M$, Tournaye $H$, Joris $H$, Verheyen $G$, Devroey $P$, et al. Cytogenetics of infertile men. Hum Reprod. 1996;11(Suppl 4):1-24 discussion 5-6.

4. Fu L, Xiong DK, Ding XP, Li C, Zhang LY, Ding M, et al. Genetic screening for chromosomal abnormalities and $Y$ chromosome microdeletions in Chinese infertile men. J Assist Reprod Genet. 2012;29(6):521-7.

5. Oliva R, Margarit E, Ballescá JL, Carrió A, Sánchez A, Milà M, et al. Prevalence of $Y$ chromosome microdeletions in oligospermic and azoospermic candidates for intracytoplasmic sperm injection. Fertil Steril. 1998;70(3):506-10.

6. Oates RD, Silber S, Brown LG, Page DC. Clinical characterization of 42 oligospermic or azoospermic men with microdeletion of the AZFc region of the $Y$ chromosome, and of 18 children conceived via ICSI. Hum Reprod. 2002;17(11):2813-24

7. Bojesen A, Juul S, Gravholt CH. Prenatal and postnatal prevalence of Klinefelter syndrome: a national registry study. J Clin Endocrinol Metab. 2003;88(2):622-6.

8. Rives N, Milazzo JP, Perdrix A, Castanet M, Joly-Hélas G, Sibert L, et al. The feasibility of fertility preservation in adolescents with Klinefelter syndrome. Hum Reprod. 2013;28(6):1468-79.

9. Samplaski MK, Lo KC, Grober ED, Millar A, Dimitromanolakis A, Jarvi KA. Phenotypic differences in mosaic Klinefelter patients as compared with non-mosaic Klinefelter patients. Fertil Steril. 2014;101(4):950-5.

10. Kuroda-Kawaguchi T, Skaletsky H, Brown LG, Minx PJ, Cordum HS, Waterston $\mathrm{RH}$, et al. The AZFC region of the $\mathrm{Y}$ chromosome features massive palindromes and uniform recurrent deletions in infertile men. Nat Genet. 2001;29(3):279-86.

11. Kleiman SE, Almog R, Yogev L, Hauser R, Lehavi O, Paz G, et al. Screening for partial AZFa microdeletions in the $Y$ chromosome of infertile men: is it of clinical relevance? Fertil Steril. 2012;98(1):43-7.

12. Stahl PJ, Masson P, Mielnik A, Marean MB, Schlegel PN, Paduch DA. A decade of experience emphasizes that testing for $Y$ microdeletions is essential in American men with azoospermia and severe oligozoospermia. Fertil Steril. 2010;94(5):1753-6.

13. Repping S, Skaletsky H, Lange J, Silber S, Van Der Veen F, Oates RD, et al. Recombination between palindromes $\mathrm{P} 5$ and $\mathrm{P} 1$ on the human $\mathrm{Y}$ chromosome causes massive deletions and spermatogenic failure. Am J Hum Genet. 2002;71(4):906-22.

14. Lin YW, Hsu LC, Kuo PL, Huang WJ, Chiang HS, Yeh SD, et al. Partial duplication at AZFc on the $Y$ chromosome is a risk factor for impaired spermatogenesis in Han Chinese in Taiwan. Hum Mutat. 2007;28(5):486-94.

15. Giachini C, Laface I, Guarducci E, Balercia G, Forti G, Krausz C. Partial AZFC deletions and duplications: clinical correlates in the Italian population. Hum Genet. 2008;124(4):399-410.

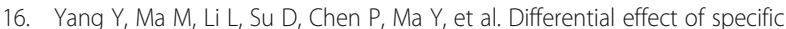
$\mathrm{gr} / \mathrm{gr}$ deletion subtypes on spermatogenesis in the Chinese Han population. Int J Androl. 2010;33(5):745-54

17. Ramasamy R, Ricci JA, Palermo GD, Gosden LV, Rosenwaks Z, Schlegel PN. Successful fertility treatment for Klinefelter's syndrome. J Urol. 2009;182(3): 1108-13.

18. Okada H, Goda K, Yamamoto Y, Sofikitis N, Miyagawa I, Mio Y, et al. Age as a limiting factor for successful sperm retrieval in patients with nonmosaic Klinefelter's syndrome. Fertil Steril. 2005;84(6):1662-4.

19. Krausz C, Hoefsloot $L$, Simoni M, Tüttelmann F, Andrology EAo, network EMGQ EAA/EMQN best practice guidelines for molecular diagnosis of $Y$-chromosomal microdeletions: state-of-the-art 2013. Andrology. 2014;2(1):5-19.

20. Schlegel PN. Testicular sperm extraction: microdissection improves sperm yield with minimal tissue excision. Hum Reprod. 1999;14(1):131-5.

21. Coerdt W, Rehder H, Gausmann I, Johannisson R, Gropp A. Quantitative histology of human fetal testes in chromosomal disease. Pediatr Pathol. 1985;3(2-4):245-59.

22. Aksglaede L, Wikström AM, Rajpert-De Meyts E, Dunkel L, Skakkebaek NE, Juul A. Natural history of seminiferous tubule degeneration in Klinefelter syndrome. Hum Reprod Update. 2006;12(1):39-48.

23. Wikström AM, Hoei-Hansen CE, Dunkel L, Rajpert-De ME. Immunoexpression of androgen receptor and nine markers of maturation in the testes of adolescent boys with Klinefelter syndrome: evidence for degeneration of germ cells at the onset of meiosis. J Clin Endocrinol Metab. 2007;92(2):714-9. 
24. Rohayem J, Fricke R, Czeloth K, Mallidis C, Wistuba J, Krallmann C, et al. Age and markers of Leydig cell function, but not of Sertoli cell function predict the success of sperm retrieval in adolescents and adults with Klinefelter's syndrome. Andrology. 2015;3(5):868-75.

25. Koga M, Tsujimura A, Takeyama M, Kiuchi H, Takao T, Miyagawa Y, et al. Clinical comparison of successful and failed microdissection testicular sperm extraction in patients with nonmosaic Klinefelter syndrome. Urology. 2007; 70(2):341-5.

26. Schiff JD, Palermo GD, Veeck LL, Goldstein M, Rosenwaks Z, Schlegel PN. Success of testicular sperm extraction [corrected] and intracytoplasmic sperm injection in men with Klinefelter syndrome. J Clin Endocrinol Metab. 2005;90(11):6263-7.

27. Navarro-Costa P, Gonçalves J, Plancha CE. The AZFc region of the $Y$ chromosome: at the crossroads between genetic diversity and male infertility. Hum Reprod Update. 2010;16(5):525-42.

28. Bansal SK, Jaiswal D, Gupta N, Singh K, Dada R, Sankhwar SN, et al. Gr/gr deletions on Y-chromosome correlate with male infertility: an original study, meta-analyses, and trial sequential analyses. Sci Rep. 2016;6:19798.

29. de Carvalho CM, Zuccherato LW, Fujisawa M, Shirakawa T, Ribeiro-dosSantos AK, Santos SE, et al. Study of AZFc partial deletion gr/gr in fertile and infertile Japanese males. J Hum Genet. 2006;51(9):794-9.

30. Wu B, Lu NX, Xia YK, Gu AH, Lu CC, Wang W, et al. A frequent Y chromosome b2/b3 subdeletion shows strong association with male infertility in Han-Chinese population. Hum Reprod. 2007;22(4):1107-13.

31. Yang Y, Ma M, Li L, Zhang W, Xiao C, Li S, et al. Evidence for the association of Y-chromosome haplogroups with susceptibility to spermatogenic failure in a Chinese Han population. J Med Genet. 2008;45(4):210-5.

32. Navarro-Costa P, Pereira L, Alves C, Gusmão L, Proença C, Marques-Vidal P, et al. Characterizing partial AZFc deletions of the $Y$ chromosome with amplicon-specific sequence markers. BMC Genomics. 2007;8:342.

33. Zhang F, Lu C, Li Z, Xie P, Xia Y, Zhu X, et al. Partial deletions are associated with an increased risk of complete deletion in AZFc: a new insight into the role of partial AZFc deletions in male infertility. J Med Genet. 2007;44(7): 437-44

34. Repping S, van Daalen SK, Korver CM, Brown LG, Marszalek JD, Gianotten J, et al. A family of human $Y$ chromosomes has dispersed throughout northern Eurasia despite a 1.8-Mb deletion in the azoospermia factor $\mathrm{c}$ region. Genomics. 2004;83(6):1046-52.

35. Krausz C, Quintana-Murci L, Forti G. Y chromosome polymorphisms in medicine. Ann Med. 2004;36(8):573-83.

36. Li LX, Dai HY, Ding XP, Zhang YP, Zhang XH, Ren HY, et al. Investigation of AZF microdeletions in patients with Klinefelter syndrome. Genet Mol Res. 2015;14(4):15140-7.

37. Corona G, Pizzocaro A, Lanfranco F, Garolla A, Pelliccione F, Vignozzi L, et al. Sperm recovery and ICSI outcomes in Klinefelter syndrome: a systematic review and meta-analysis. Hum Reprod Update. 2017;23(3):265-75.

\section{Publisher's Note}

Springer Nature remains neutral with regard to jurisdictional claims in published maps and institutional affiliations.

Ready to submit your research? Choose BMC and benefit from:

- fast, convenient online submission

- thorough peer review by experienced researchers in your field

- rapid publication on acceptance

- support for research data, including large and complex data types

- gold Open Access which fosters wider collaboration and increased citations

- maximum visibility for your research: over $100 \mathrm{M}$ website views per year

At $\mathrm{BMC}$, research is always in progress.

Learn more biomedcentral.com/submissions 